\title{
Developing a brief acceptance and commitment therapy model for industrial psychologists
}

\begin{tabular}{|c|c|}
\hline \multicolumn{2}{|c|}{$\begin{array}{l}\text { Authors: } \\
\text { Xander van Lill } 10 \\
\text { Rinet van Lill² }\end{array}$} \\
\hline \multicolumn{2}{|c|}{$\begin{array}{l}\text { Affiliations: } \\
\text { 'Department of Industrial } \\
\text { Psychology and People } \\
\text { Management, College of } \\
\text { Business and Economics, } \\
\text { University of Johannesburg, } \\
\text { Johannesburg, South Africa }\end{array}$} \\
\hline \multicolumn{2}{|c|}{$\begin{array}{l}{ }^{2} \text { Gauteng Department of } \\
\text { Health, Bertha Gxowa } \\
\text { Hospital, Johannesburg, } \\
\text { South Africa }\end{array}$} \\
\hline \multicolumn{2}{|c|}{$\begin{array}{l}\text { Corresponding author: } \\
\text { Xander van Lill, } \\
\text { xvanlill@gmail.com }\end{array}$} \\
\hline \multicolumn{2}{|c|}{$\begin{array}{l}\text { Dates: } \\
\text { Received: } 19 \text { Mar. } 2021 \\
\text { Accepted: } 03 \text { Dec. } 2021 \\
\text { Published: } 25 \text { Feb. } 2022\end{array}$} \\
\hline \multicolumn{2}{|c|}{$\begin{array}{l}\text { How to cite this article: } \\
\text { Van lill, X., \& Van Lill, R. } \\
\text { (2022). Developing a brief } \\
\text { acceptance and commitment } \\
\text { therapy model for industrial } \\
\text { psychologists. SA Journal of } \\
\text { Industrial Psychology/SA } \\
\text { Tydskrif vir Bedryfsielkunde, } \\
\text { 48(0), a1897. https://doi. } \\
\text { org/10.4102/sajip.v48i0.1897 }\end{array}$} \\
\hline \multicolumn{2}{|c|}{$\begin{array}{l}\text { Copyright: } \\
\text { (c) 2022. The Authors. } \\
\text { Licensee: AOSIS. This wo } \\
\text { is licensed under the } \\
\text { Creative Commons } \\
\text { Attribution License. }\end{array}$} \\
\hline \multicolumn{2}{|l|}{ Read online: } \\
\hline 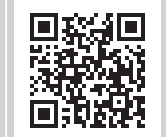 & $\begin{array}{l}\text { Scan this QR } \\
\text { code with your } \\
\text { smart phone or } \\
\text { mobile device } \\
\text { to read online. }\end{array}$ \\
\hline
\end{tabular}

Orientation: Mental health distress is on the rise, which has significant implications for labour productivity. Industrial psychologists, who are equipped to offer work-based counselling, can play a vital role in alleviating this burden.

Research purpose: This study was an investigation of current literature on industrial psychologists as counsellors, with a focus on acceptance and commitment therapy (ACT) as a framework to deliver brief work-based counselling. The aim was to offer a practical model of counselling, derived from the literature, for industrial psychologists to perform work-based counselling.

Motivation for the study: There is a paucity of literature pertaining to evidence-based guidelines that industrial psychologists can follow to provide counselling. This study attempts to expand industrial psychologists' counselling skill set by proposing an ACT intervention that can be applied as a brief counselling process in the workplace.

Research approach/design and method: A systematic literature review of three separate literature streams yielded 1297 publications. After further analysis, 25 publications that met the criteria for relevance and quality were considered to create a model for workplace counselling.

Main findings: Attention to the role of industrial psychologists as counsellors dwindled after the 1960s but has recently been given renewed attention by South African scholars. The literature review of experimental ACT designs revealed evidence-based guidelines that were combined to create the ACT for Work Well-being Model.

Practical/managerial implications: The ACT for Work Well-being Model is a brief counselling protocol to offer systematic steps that industrial psychologists can implement during brief work-based counselling to address anxiety and depressive symptoms.

Contribution/value-add: The proposed model is designed to stimulate further empirical validation and ensure evidence-based practice.

Keywords: work-based counselling; acceptance and commitment therapy; mental health; industrial psychology; brief therapy.

\section{Introduction}

According to the latest global data, mental health and substance abuse account for one-fifth of years of disability, which is a significant increase from previous decades (World Health Organization [WHO], 2020). Whilst the latest data from the WHO (2017) suggests that $4.6 \%$ of the South African population might struggle with depression and $3.4 \%$ with anxiety, the respective statistics might be three to four times higher because of the COVID-19 pandemic (Cénat et al., 2021). South Africa has made progress in establishing mental health policies and supportive legislation, but Docrat, Besada, Cleary, Daviaud and Lund (2019) reported that of the $84 \%$ of South Africans without medical aid, around $92 \%$ do not receive any care for mental health concerns. A study conducted by Mall et al. (2015) revealed that anxiety and depression resulted in the greatest number of out-of-role days (28.2 and 27.2 days per year, respectively) when compared with substance abuse, headaches, arthritis, pain, cardiovascular problems, respiratory illness, diabetes and digestive problems. This significant loss of labour productivity because of depression and anxiety demands focussed attention from organisations.

Van Vuuren (2010) emphasised the importance of industrial psychology as a profession to employ a humanistic orientation, alongside commercial goals to contribute to greater societal good. In the midst of debates on industrial psychologists' role as counsellors, several scholars have argued the importance of industrial psychologists acting in a counselling capacity within the South African 
context (Barkhuizen, Jorgensen, \& Brink, 2014; Barnard \& Fourie, 2007; Du Plessis \& Thomas, 2021; Strümpfer, 2007). However, South African industrial psychologists reported insufficient preparedness to offer such counselling (Barkhuizen, Jorgensen \& Brink, 2015; Du Plessis \& Thomas, 2021).

The Health Professions Council of South Africa (HPCSA, 2019a) specified that the minimum standards for the training of industrial psychologists should include skills in individual or group counselling to address trauma, crises or outcomes related to job stress. The HPCSA (2019a) further stipulated that industrial psychologists should provide short-term counselling, making brief therapeutic approaches most suitable. A brief therapy approach is also a cautious strategy to ensure that industrial psychologists are not involved when an employee's mental health condition exceeds their professional capacity. Guidelines on a counselling approach that fits the industrial psychologist's professional capacity and intentions could offer a helpful way to address mental health concerns in the workplace.

\section{Purpose of the study}

The purpose of this study is to conduct a systematic literature review, aimed at formulating guidelines that could empower industrial psychologists to provide work-based counselling interventions. As a result of the prevalence of depression and anxiety in South Africa, these two symptom clusters were chosen to demarcate the scope of the study.

\section{Current theoretical perspective}

\section{Work-based counselling}

Aside from the increase in mental health diagnoses observed worldwide, workplaces bring a unique set of risk factors that could detrimentally affect employees' mental health (Harvey et al., 2017). According to Barkhuizen et al. (2014), counselling can include facilitation to guide people through a problem by increasing self-insight and empowerment and advancing optimal functioning. Counselling is a minimum skill required by industrial psychologists and relevant to other functions such as career guidance, psychometric feedback, performance management, retrenchment and occupational safety (HPCSA, $2019 b)$. As mental health conditions are associated with a loss of productivity (Stepanek, Jahanshahi, \& Millard, 2019), it is important that industrial psychologists are equipped to intervene. A literature review demonstrated the potential of work-based interventions for mental health conditions, to improve absence duration, economic outcomes, quality of life and work functioning (Pomaki, Franche, Murray, Khushrushahi, \& Lampinen, 2012). Counselling is an effective intervention to address the mental health challenges of employees (Collins et al., 2012; McLeod, 2010).

\section{The viability for acceptance and commitment therapy as an approach to work-based counselling}

Although there are many different counselling approaches, Minjoo, Mpofu, Brock, Millington and Athanasou (2014) found evidence for cognitive behavioural therapy (CBT) in the workplace, which holds promise as an intervention for industrial psychologists to address mental illness. ACT is recognised as a third-wave CBT therapy that is aimed at addressing mental health issues through enhancing psychological flexibility (Hayes, Strosahl, Luoma, Varra, \& Wilson, 2004). Psychological flexibility is the ability to make contact with the present moment, without judging private experiences (e.g. cognitions and emotions) and a willingness to change action plans that do not serve meaningful life goals (Hayes, Strosahl, \& Wilson, 2012). Meta-analytical evidence supports the efficacy of ACT in addressing mental health concerns such as anxiety and depression (Gloster, Walder, Levin, Twohig, \& Karekla, 2020). There is also growing literature on the use of ACT as a brief intervention (Strosahl, Robinson, \& Gustavsson, 2012), which is considered more appropriate for the industrial psychologist's involvement in work-based counselling (Du Plessis \& Thomas, 2021; JorgensenGraupner \& Van Zyl, 2019).

In ACT, psychological flexibility is facilitated through six processes that will be discussed according to three response styles and the definitions provided by Hayes et al. (2012).

Open response style: Acceptance and defusion are critical elements that help facilitate a non-judgemental and more holistic understanding of direct experience. Acceptance is a process of enhancing willingness to attend to difficult inner experiences (including cognitions, emotions, memories and physical sensations). Defusion makes it possible to untangle from unhelpful inner experiences to the extent that it does not dictate behaviour.

Centred response style: A centred response style aids a mindful approach to everyday experience and includes two processes: Attention to the present moment involves a flexible shift in attention that is non-judging and allows greater awareness of private experiences. Self-as-context is about broadening perspectives regarding definitions of the self in an effort to combat limiting and self-defeating conceptualisations.

Engaged response style: Values and committed action are crucial for living a meaningful life. Values that are freely chosen and give purpose in life are explored whilst committed action involves a continuing set of behaviours, aimed at living according to values.

ACT is a structured approach to therapy and incorporates psychological skills that industrial psychologists might be more familiar with, such as goal-setting, reinforcing reasonable thinking and behavioural modification.

\section{Problem statement and research objectives}

Although industrial psychologists are likely to encounter a need for work-based counselling, many practitioners still 
report low self-efficacy in providing brief therapy (Du Plessis \& Thomas, 2021; Jorgensen-Graupner \& Van Zyl, 2019). There is also a paucity of literature offering clear guidelines for industrial psychologists to perform work-based counselling. A systematic literature review was conducted with the following two objectives:

1. To investigate existing guidelines on the role of industrial psychologists as work-based counsellors.

2. To establish evidence-based guideline from brief ACT that industrial psychologists can use to provide counselling for anxiety and depression in the workplace.

\section{Value-add of the study}

The systematic literature review provided an overview of available studies regarding industrial psychologists' role as counsellors, together with an integrated summary of experimental studies conducted to validate ACT as a brief therapeutic framework within and outside the workplace. Evidence-based protocols from the ACT literature review were combined to develop the ACT for Work Well-being Model, which is a practical model that can be implemented by industrial psychologists and a training model that can be used to teach work-based counselling knowledge and skills to emerging psychologists.

\section{Research design \\ Research approach}

A systematic literature review offers a way to ascertain the current state of studies in addressing a research objective. Systematic literature reviews aim to synthesise one or more sources, in order to provide an overall impression of the evidence in relation to a particular research question and to clarify what is known and not known within a field (Nightingale, 2009; Siddaway, Wood, \& Hedges, 2018). The guidelines of Siddaway et al. (2018) and Laher and Hassem (2020) guided this study process and are discussed in the following sections.

The systematic literature review targeted three literature streams. Stream 1 focussed on literature on existing counselling practices of industrial psychologists with the aim to investigate the support for and current scope of practical guidelines regarding counselling in the workplace for industrial psychologists. Provided the dearth of literature that was previously reported (Jorgensen, 2016; Jorgensen-Graupner \& Van Zyl, 2019), this study also explored ACT as a viable therapeutic framework to offer guidelines on conducting work-based counselling. Therefore, an investigation of evidencebased guidelines that could be used to inform a brief work-based ACT model for the workplace followed in Stream 2. Stream 3 continued to include evidence-based studies on ACT as a brief therapy outside of the workplace in order to consider additional guidelines for developing such a protocol.

\section{Targeted body of literature}

Two electronic databases were identified to conduct systematic literature searches, namely PsycInfo and Sabinet. PsycInfo provides access to social science and behavioural research globally, whereas Sabinet focusses on African electronic journals and allows access to African studies that are not always available to the global North (Laher \& Hassem, 2020). The search included the following keywords with Boolean operator 'AND':

1. 'Industrial and organisational psychology' AND 'Counselling'

2. 'Acceptance and commitment therapy (ACT)' AND 'Workplace'

3. 'Acceptance and commitment therapy' AND 'Brief'

Whilst 'industrial and organisational psychology' is the most appropriate term to use in PsycInfo, 'industrial psychology' was used in the Sabinet search, in accordance with South African terminology. Work-based counselling rose to eminence in the 1940s (Highhouse, 1999) and the search for Stream 1 considered publications from 1940 to 2020. The ACT literature emerged in the 1980s, and the literature review included only literature published from 1980 to 2020 .

\section{Gathering the data}

As displayed in Figure 1, the initial search yielded 1297 publications (703 from PsycInfo and 594 from Sabinet). Screening followed to distinguish articles relevant to answering the research question and that were of an acceptable quality. Included articles had to be written in English or Afrikaans, and samples of studies were restricted to adults of the age of majority in South Africa (18 years or older). Peer-reviewed publications are considered more rigorous; therefore, grey literature (publications not subject to the blind peer-review process) was excluded (Hassem \& Laher, 2019). Each stream of literature had further criteria for inclusion and exclusion, namely:

1. Publications had to explicitly mention the industrial and/ or organisational psychologist as counsellor. Literature

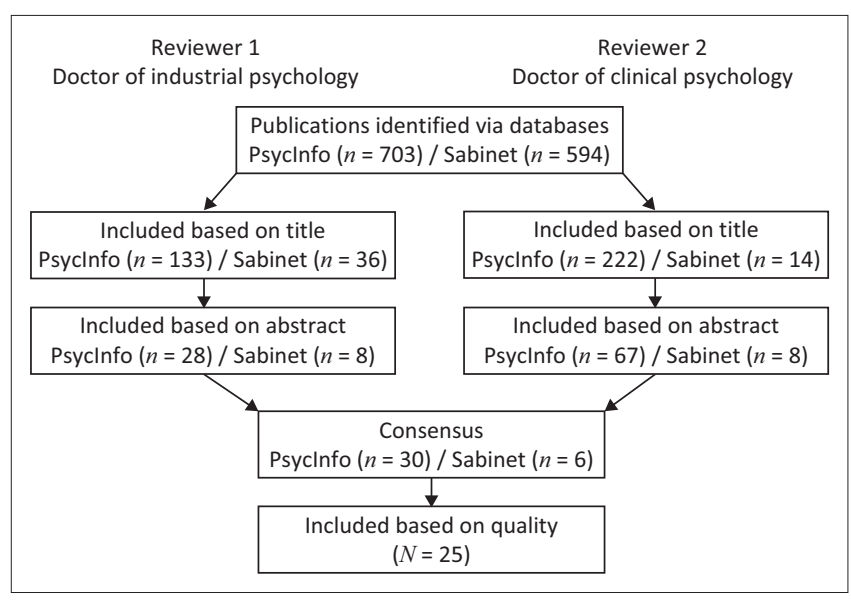

Source: Adapted with permission from Hassem, T., \& Laher, S. (2019). A systematic review of online depression screening tools for use in the South African context. South African Journal of Psychiatry, 25, 1-8. https://doi.org/10.4102/sajpsychiatry.v25i0.1373

FIGURE 1: Flow diagram of articles that were included and excluded. 
Stream 1 did not include literature that focused on the role of clinical and counselling psychologists in the workplace.

2. Publications that did not explicitly mention ACT as applied in the workplace were excluded in Stream 2. The search was restricted to randomised control trails aimed at addressing anxiety or depressive symptoms.

3. For Stream 3, the literature search included publications since 1980 with an explicit mention of ACT in a brief application. As with Stream 2, the search contained only randomised control trails aimed at addressing anxiety or depressive symptoms.

The authors (an industrial psychologist and a clinical psychologist with doctoral degrees in their respective fields) conducted independent screening processes to determine the eligibility of the publications for inclusion. The screening process proposed by Hassem and Laher (2019) was utilised, namely researchers should first screen titles, then abstracts and then full texts to ascertain the relevance of each article, before establishing consensus between the two reviewers on publications to include in the review. Inspection of the quality of the publications was the final step in the screening process. Articles related to the role of the industrial psychologist as counsellor was limited in scope and, therefore, all articles were included. The rating system proposed by the Critical Appraisal Skills Programme (2020, p. 1) provides 11 key considerations to determine the validity and applicability of randomised control trails in Streams 2 and 3, of which 10 were considered relevant and used as guidelines. The guidelines are listed as follows:

1. Did the study address a clearly focussed research question?

2. Was the assignment of participants to interventions randomised?

3. Were all participants who entered the study accounted for at its conclusion?

4. Were the study groups similar at the start of the randomised control trail?

5. Apart from the experimental intervention, did each study group receive the same level of care (i.e. were they treated equally)?

6. Were the effects of the intervention reported comprehensively?

7. Was the precision of the estimate of the intervention or treatment effect reported?

8. Do the benefits of the intervention outweigh the harms and costs?

9. Can the results be applied to your local population in your context?

10. Would the experimental intervention provide greater value to the people in your care than any of the existing interventions?

As suggested by Question 1, only randomised controlled trials were included to determine whether a protocol could be constructed from a causally valid evidence base (Lilienfeld, McKay, \& Hollon, 2018). Although none of the studies from Streams 2 and 3 were conducted in South Africa, per Question 9, ACT is regarded as a unified and transdiagnostic framework, which is applicable to many contexts (Hayes et al., 2012). One ACT randomised control trial, conducted in South Africa, showed significant effect sizes for improvement in quality of life and seizure frequency in people who suffer from epilepsy (Lundgren, Dahl, Melin, \& Kies, 2006). Question 9 also concerns the relevance of the studies to the practices of South African industrial psychologists. The literature from Stream 3 was not specific to industrial psychologists (i.e. applicable to the work context), but there was sufficient convergence with the protocols found in Stream 2 to suggest applicability for industrial psychologists.

The elimination process yielded a total of 25 publications for inclusion as illustrated in Figure 1.

\section{Analysis of the data}

In a systematic review, content analyses are usually implemented in a quantitative manner to code specific categories, which are then reported using descriptive statistics (Laher \& Hassem, 2020). In this study, the content analysis focused on the following categories: author, design and participants, procedures, measures of outcomes and results. Calculations of frequencies and percentages provide an indication of the elements on which the studies in literature Streams 2 and 3 converged in terms of methods and results reported.

\section{Results}

The results from the three different streams are summarised in Tables 1 to 3 . Table 1 provides a summary of literature pertaining to the historical role of industrial psychologists as counsellors and existing guidelines on workplace counselling for industrial psychologists. Table 2 includes experimental studies that reported on ACT protocols for workplace counselling and Table 3 contains a list of articles found on the application of brief ACT models.

\section{Stream 1: Industrial psychologists and work- based counselling}

As presented in Table 1, industrial psychologists' role as work-based counsellors rose to prominence as a result of the work of Elton Mayo and the Hawthorne research team, who started investigations into the influence of work environments on employees (Highhouse, 1999). In literature Stream 1, all four publications emanating from the United States of America focus on the Hawthorne experiments and the counselling programme incorporated at this industrial electric plant. Attention to the counselling role of industrial psychologists dwindled in the 1960s (Highhouse, 1999), and literature Stream 1 revealed rising prominence as a result of the work of South African authors. Two of these studies highlighted counselling as a function of industrial psychology (Barnard \& Fourie, 2007; Van Zyl, Nel, Stander, \& Rothmann, 2016). Qualitative studies by Barkhuizen et al. (2014) provided greater insight into industrial psychologists' perceptions of counselling, and Barkhuizen et al. (2015) raised concerns regarding 
TABLE 1: Industrial psychology and counselling.

\begin{tabular}{|c|c|c|}
\hline Author & Design and participants & Result \\
\hline $\begin{array}{l}\text { - Barkhuizen et al. (2014) } \\
\text { - South Africa }\end{array}$ & $\begin{array}{l}\text { - A total of } 22 \text { registered } \\
\text { IPs } \\
\text { - Qualitative } \\
\text { - Semi-structured } \\
\text { interviews }\end{array}$ & $\begin{array}{l}\text { Themes: } \\
\text { - Meaning of counselling } \\
\text { - Counselling situations } \\
\text { - Recommendations for } \\
\text { training } \\
\text { - Include counselling in } \\
\text { IP scope }\end{array}$ \\
\hline $\begin{array}{l}\text { - Barkhuizen et al. (2015) } \\
\text { - South Africa }\end{array}$ & $\begin{array}{l}\text { - A total of } 22 \text { registered } \\
\text { IPs } \\
\text { - Qualitative } \\
\text { - Semi-structured } \\
\text { interviews }\end{array}$ & $\begin{array}{l}\text { Themes: } \\
\text { - Counselling skills required } \\
\text { - Types of academic } \\
\text { training } \\
\text { - Insufficient practical } \\
\text { training } \\
\text { - Additional training } \\
\text { received } \\
\text { - Recommendations for } \\
\text { future training }\end{array}$ \\
\hline $\begin{array}{l}\text { - Barnard and Fourie } \\
\text { (2007) } \\
\text { - South Africa }\end{array}$ & $\begin{array}{l}\text { - A total of } 23 \text { registered } \\
\text { IPs } \\
\text { - Qualitative } \\
\text { - Semi-structured } \\
\text { interviews }\end{array}$ & $\begin{array}{l}\text { Theme: } \\
\text { - Ips consider counselling } \\
\text { part of professional role }\end{array}$ \\
\hline $\begin{array}{l}\text { - Cantor (1945) } \\
\text { - United States of America }\end{array}$ & Not applicable & $\begin{array}{l}\text { Documents IP's role as } \\
\text { counsellor at Western } \\
\text { Electric's Hawthorne Plant }\end{array}$ \\
\hline $\begin{array}{l}\text { - Dickson (1945) } \\
\text { - United States of America }\end{array}$ & Not applicable & $\begin{array}{l}\text { Documents IP's role as } \\
\text { counsellor at Western } \\
\text { Electric's Hawthorne Plant }\end{array}$ \\
\hline $\begin{array}{l}\text { - Highhouse (1999) } \\
\text { - United States of America }\end{array}$ & Not applicable & $\begin{array}{l}\text { Discusses rise and fall of } \\
\text { work-based counselling }\end{array}$ \\
\hline $\begin{array}{l}\text { - Jorgensen (2016) } \\
\text { - South Africa }\end{array}$ & $\begin{array}{l}\text { - A total of } 48 \text { IP master's } \\
\text { students } \\
\text { - Qualitative } \\
\text { - Structured observation }\end{array}$ & $\begin{array}{l}\text { Intervention increased: } \\
\text { - Intrapersonal awareness } \\
\text { - Interpersonal awareness } \\
\text { - Group awareness }\end{array}$ \\
\hline $\begin{array}{l}\text { - Jorgensen-Graupner and } \\
\text { Van Zyl (2019) } \\
\text { - South Africa }\end{array}$ & Not applicable & $\begin{array}{l}\text { Proposes counselling } \\
\text { framework for IPs based } \\
\text { on four phases: rooting, } \\
\text { growing, branching, and } \\
\text { thriving }\end{array}$ \\
\hline $\begin{array}{l}\text { - Minjoo et al. (2014) } \\
\text { - South Africa }\end{array}$ & $\begin{array}{l}\text { - A total of } 11 \text { articles } \\
\text { identified } \\
\text { - Systematic review }\end{array}$ & $\begin{array}{l}52.1 \% \text { of studies indicate } \\
\text { that CBT improves: } \\
\text { - psychological functioning } \\
\text { - symptoms } \\
\text { - self-esteem } \\
\text { - psychosocial functioning } \\
\text { - Authors recommend CBT } \\
\text { for IPs }\end{array}$ \\
\hline $\begin{array}{l}\text { - Van Zyl, Nel, Stander and } \\
\text { Rothmann (2016) } \\
\text { - South Africa }\end{array}$ & $\begin{array}{l}\text { - A total of } 151 \text { registered } \\
\text { IPs } \\
\text { - Qualitative }\end{array}$ & $\begin{array}{l}\text { - Highlights brief } \\
\text { counselling as an IP } \\
\text { function }\end{array}$ \\
\hline $\begin{array}{l}\text { - Wilensky and Wilensky } \\
\text { (1951) } \\
\text { - United States of America }\end{array}$ & Not applicable & $\begin{array}{l}\text { Documents IP's role as } \\
\text { counsellor at Western } \\
\text { Electric's Hawthorne Plant }\end{array}$ \\
\hline
\end{tabular}

$\mathrm{CBT}$, cognitive behavioural therapy; IPs, industrial psychologists

limitations in training. Jorgensen-Graupner and Van Zyl (2019) offered a broader therapeutic framework. Minjoo et al. (2014) conducted a literature review, which supported CBT as a viable counselling framework to improve employee outcomes. However, none of the publications in Stream 1 provided specific guidelines that could assist industrial psychologists who are novices at providing counselling. These findings emphasise the dearth of guidelines available to industrial psychologists to conduct work-based counselling, necessitating further exploration of literature found in Streams 2 and 3.

\section{Streams 2 and 3: Evidence for acceptance and commitment therapy protocols in the workplace and as brief therapy}

As a result of overlap between the study designs found in Streams 2 and 3, the results will be discussed together. The literature consisted of randomised control trails with varied populations, namely employees ( $n=6$ out of $14 ; 43 \%$ ), students ( $n=3$ out of $14 ; 21 \%$ ) and self-referred clients
( $n=5$ out of $14 ; 36 \%)$. Several studies used pre-screening procedures $(n=12$ out of $14 ; 86 \%)$, and, in most cases, a specified presentation or severity of pathology was demarcated. The identified participants were then assigned to different experimental conditions, namely ACT (or an adaption thereof), alternative therapies ( $n=7$ out of 14 ; $50 \%)$, and / or a control group ( $n=9$ out of $14 ; 64 \%)$. Trained professionals ( $n=5$ out of $14 ; 36 \%$ ) or postgraduate students of psychology ( $n=8$ out of $14 ; 57 \%)$ provided ACT interventions aimed at individuals ( $n=9$ out of $14 ; 64 \%$ ) or groups ( $n=6$ out of $14 ; 43 \%$ ), which took place over the course of one to six sessions. In line with ACT principles, most of the interventions included experiential exercises ( $n=12$ out of $14 ; 86 \%$ ) and many included homework assignments ( $n=9$ out of $14 ; 64 \%)$. Outcome measures were used to determine the effectiveness of therapies across time and condition and included instruments to evaluate anxiety and depressive states $(n=14$ out of $14 ; 100 \%)$. Frequently used outcome measures included the General Health Questionnaire (GHQ) $(n=6$ out of $14 ; 43 \%)$, the Beck Depression Inventory (BDI) $(n=7$ out of $14 ; 50 \%)$, the Maslach Burnout Inventory (MBI) $(n=3 ; 21 \%)$ and the Perceived Stress Scale (PSS) $(n=3 ; 21 \%)$. Process measures, such as the Acceptance and Action Questionnaire (AAQ) ( $n=9$ out of $14 ; 64 \%$ ), were frequently administrated. The evidence from Streams 2 and 3 suggests that ACT consistently improves anxiety and depressive symptoms across time ( $n=8$ out of $14 ; 57 \%$ ). However, in most of the experiential studies, ACT $(n=2$ out of $7 ; 29 \%)$ did not outperform alternative therapies ( $n=6$ out of $7 ; 86 \%$ ).

\section{Discussion}

The purpose of the study was to provide guidelines regarding the application of work-based counselling by industrial psychologists. The results from the literature review in Stream 1 confirms a paucity in this body of literature, which might contribute to South African industrial psychologists' perception of being ill-prepared for the role of counsellor. Streams 2 and 3 yielded literature that provides practical guidelines to industrial psychologists on the application of ACT interventions to reduce anxiety and depression-related symptoms. Clear recommendations on the provision of work-based counselling that is evidencebased can enhance South African industrial psychologists' competence and confidence in their role as counsellors. Protocols from Streams 2 and 3 guided the design of the ACT for Work Well-being Model by the authors and are presented in Figure 2.

\section{Acceptance and commitment therapy for Work Well-being Model}

Although symptom reduction is not the ultimate hallmark of ACT, enhanced psychological flexibility is associated with reduced psychological distress (Gloster et al., 2020). The aim of ACT for the Work Well-being Model is to alleviate the impact of depression and anxiety symptoms, through work-based counselling, by enhancing 
TABLE 2: Acceptance and commitment therapy as a work-based counselling intervention.

\begin{tabular}{|c|c|c|c|c|}
\hline Author & Design and participants & Procedure & Process and outcome measures & Results \\
\hline $\begin{array}{l}\text { - Barrett and Stewart (2020) } \\
\text { - International }\end{array}$ & $\begin{array}{l}\text { - Social and healthcare workers } \\
\text { - Pre-screening reported } \\
\text { - ACT }(n=13) \\
\text { - CBT }(n=13)\end{array}$ & $\begin{array}{l}\text { - Individual-based interventions } \\
\text { through an online programme } \\
\text { - Three sessions with videos/ } \\
\text { exercises for both conditions } \\
\text { over } 2 \text { weeks } \\
\text { - Sessions for both conditions, } \\
\text { followed by questions that track } \\
\text { attention to material and } \\
\text { experience of helpfulness } \\
\text { - Experiential exercises } \\
\text { incorporated in both conditions } \\
\text { - Homework assigned in ACT }\end{array}$ & $\begin{array}{l}\text { - Perceived Stress Scale (PSS) } \\
\text { - General Health Questionnaire } \\
12 \text { (GHQ-12) } \\
\text { - Maslach Burnout Inventory (MBI) } \\
\text { - Work-related Acceptance and } \\
\text { Action Questionnaire (WAAQ) }\end{array}$ & $\begin{array}{l}\text { Time } \\
\text { PSS: } F(1.40)=7.30 ; p<0.05 \text {; partial } \\
\eta 2=0.15 . \mathrm{ACT} \text { and CBT lowered PSS } \\
\text { score } \\
\text { GHQ-12: } F(1.40)=12.60 ; p<0.01 \text {; } \\
\text { partial } \eta 2=0.24 \text {. ACT and CBT lowered } \\
\text { GHQ score } \\
\text { MBI: } F(1.40)=4.87 ; p<0.05 ; \text { partial } \\
\eta 2=0.11 \text {. ACT and CBT lowered MBI } \\
\text { score }\end{array}$ \\
\hline $\begin{array}{l}\text { - Bond and Bunce (2000) } \\
\text { - United Kingdom }\end{array}$ & $\begin{array}{l}\text { - Employed university graduates } \\
\text { from a media organisation } \\
\text { - No pre-screening reported } \\
\text { - ACT }(n=30) \\
\text { - Innovation Promotion } \\
\text { Programme (IPP) }(n=30) \\
\text { - Control }(n=30)\end{array}$ & $\begin{array}{l}\text { - Group interventions conducted } \\
\text { by unspecified individuals } \\
\text { - Three half-day sessions of } 3.25 \\
\text { h each, occurring at weeks } 1,2 \\
\text { and } 14 \\
\text { - Experiential exercises } \\
\text { incorporated in both conditions } \\
\text { - Homework assigned in both } \\
\text { conditions }\end{array}$ & $\begin{array}{l}\text { - GHQ-12 } \\
\text { - Beck Depression Inventory (BDI) } \\
\text { - Intrinsic job motivation } \\
\text { - Intrinsic job satisfaction } \\
\text { - Propensity to innovate }\end{array}$ & $\begin{array}{l}\text { Multivariate time } \\
\text { Mul15.48) }=4.95 ; p<0.01 ; \eta 2=0.61 \\
\text { Multivariate Time* }{ }^{*} \text { Condition } \\
\text { - } F(30.98)=3.28 ; p<0.01 ; \eta 2=0.50 \text {. } \\
\text { GHQ scores lower for ACT compared } \\
\text { to IPP and control. BDI score lower in } \\
\text { ACT and IPP compared to control }\end{array}$ \\
\hline $\begin{array}{l}\text { - Flaxman and Bond (2010) } \\
\text { - United Kingdom }\end{array}$ & $\begin{array}{l}\text { - Government employees } \\
\text { - Screened participants with GHQ } \\
\text { - ACT (n=37) } \\
\text { Stress Inoculation Training (SIT) } \\
\text { - Waitlist control group (WCG) } \\
(n=33)\end{array}$ & $\begin{array}{l}\text { - Group-based interventions } \\
\text { conducted by first author } \\
\text { - Two half-day training sessions } \\
\text { of } 3 \mathrm{~h} \text { each, } 1 \text { week apart } \\
\text { - Experiential exercises } \\
\text { incorporated in both conditions }\end{array}$ & $\begin{array}{l}\text { - GHQ-12 } \\
\text { - Acceptance and Action } \\
\text { Questionnaire (AAQ) } \\
\text { - Dysfunctional Attitude Scale } \\
\text { (DAS) }\end{array}$ & $\begin{array}{l}\text { Time* Condition } \\
\text { - GHQ-12: } F(1.63)=5.31 ; p<0.01 \text {. GHQ } \\
\text { score lower for ACT }(d=1.31) \text { and SIT } \\
(d=1.21) \text { compared to control }\end{array}$ \\
\hline
\end{tabular}

Note: Only significant effects or effects trending towards significance are reported for mental health outcomes in Results.

psychological flexibility. The identification and implementation of goals, analogous to the value and committed action processes in the ACT hexaflex, takes central focus in the ACT for Work Well-being Model. Goal-setting literature from the industrial psychology body of knowledge was incorporated into the model to create greater alignment with theories that are likely to be familiar to industrial psychologists. The four remaining hexaflex processes, namely defusion, acceptance, self-ascontext and being in the present moment can be employed to establish greater psychological flexibility to circumvent barriers to goal achievement. Professionals registered as students, interns or industrial psychologists in independent practice can implement the steps provided in the model in their capacity as counsellors. Ideally, these practitioners should attend initial training and subsequent supervision by psychologists who are well-versed in ACT applications to enhance their competence in using the model.

The appropriate client population to benefit from this intervention is self-nominated working adults, who present with mild to moderate symptoms of depression and anxiety. Industrial psychologists should use validated inventories to identify employees at risk, at the outset of therapy, rather than rely on their clinical judgement, which might be biased because of limited training and exposure. The following measurements show promise to be used: the Centre for Epidemiologic Studies' Depression Scale-Revised, Generalised Anxiety Disorder Scale 7 (Henn \& Morgan, 2019), and the Depression and Anxiety Scale (Dreyer, Henn, \& Hill, 2019). These instruments should only be used by industrial psychologists to identify employees at risk and not diagnose clients, as this would be outside of their scope of 
practice, and should be referred to the appropriate professionals in severe cases (Henn \& Morgan, 2019). Four individual sessions should be scheduled weekly with homework assignments between sessions. The ACT for Work Well-being Model is divided into different acts that highlight therapeutic procedures to follow in each session, as well as intermissions that include post-session activities for clients to carry out. In the discussion that ensues, each session will start with a text box that summarises findings from the literature review that is relevant to the aim of the session (see Boxes 1 to 4 ). An example (called a scene) is provided in each session to illustrate how an ACT exercise can be utilised to facilitate the session.

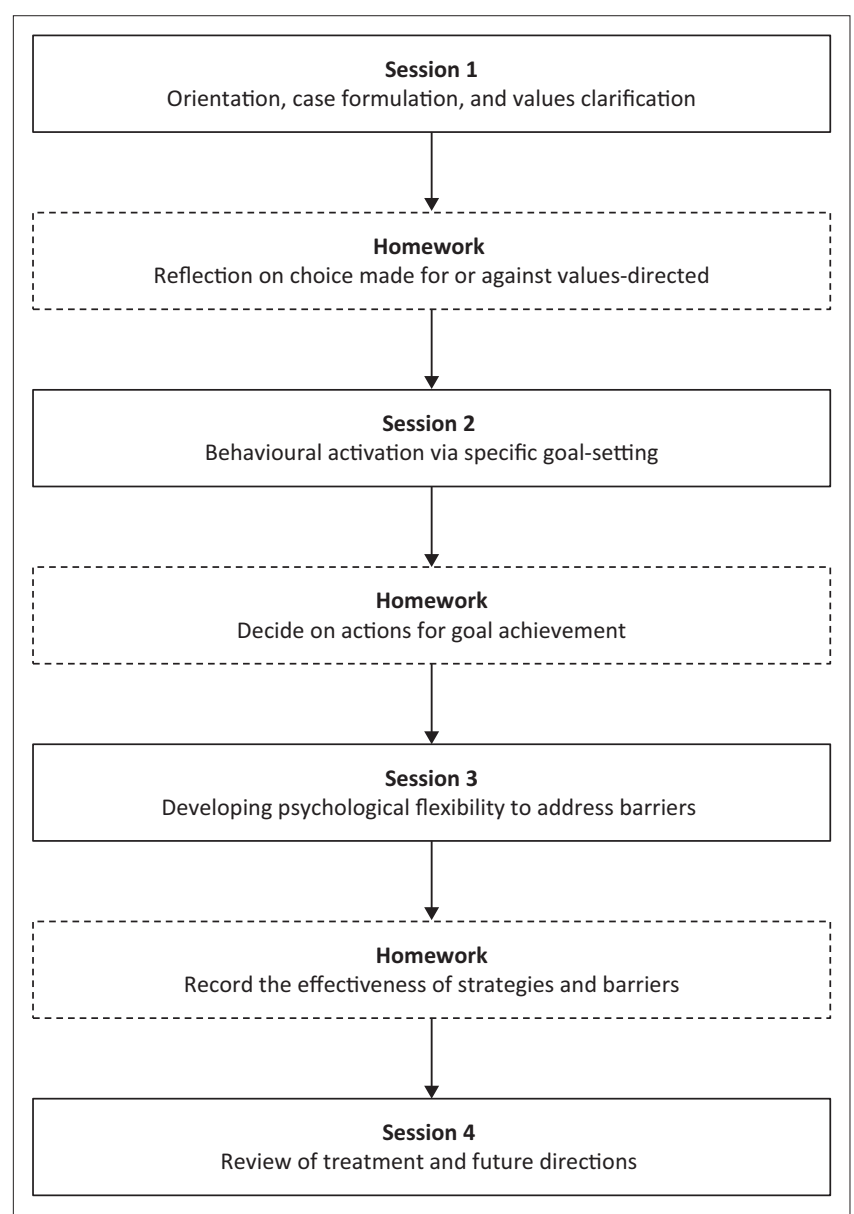

FIGURE 2: Acceptance and commitment therapy for work well-being model.

\section{Orientation, case formulation and values clarification}

BOX 1: Orientation, case formulation and values clarification.

- Incorporate rationales for using ACT at the outset of therapy in order to promote adherence to and motivation for the intervention (Barrett \& Stewart, 2020; Macías et al., 2019; Ruiz et al., 2020).

- Include a case formulation at the beginning of therapy to understand the functional impact of the presenting complaint of the client (Brinkborg, Michanek, Hesser, \& Berglund, 2011; Finnes et al., 2019; Folke et al., 2012; Kohtala et al., 2017; Macías et al., 2019).

- Add a values clarification exercise early in the therapeutic process to provide structure to subsequent sessions (Finnes et al., 2019; Folke et al., 2012; Kohtala et al., 2017; Macías et al., 2019; Pellowe, 2006).

- Give a homework exercise that will help the client to reflect on reasons for taking steps in a valued direction (Folke et al., 2012).
ACT 1 (Orientation): An orientation to the principles of ACT, and the associated aim to enhance psychological flexibility via the hexaflex model, serves to prepare the employee for therapy and promotes adherence to the conditions of the intervention. Issues surrounding informed consent and confidentiality should also be clarified at the outset of therapy to establish a psychologically safe environment where intimate details can be shared (Bond, 2004).

ACT 2 (Case formulation): Once the rules and structure of therapy is explained, a case formulation is composed. In $\mathrm{ACT}$, the focus is less on the manifestation of psychopathology and more on its functional impact on the client. The prevalence of depression, for example, has implications for how clients structure their lives and how the sense of self is defined by the presence of depression (Hayes et al., 2004). Two questions, central to the case formulation are: (1) 'What kind of life does the client most deeply want to create and love?' and (2) 'What are the psychological and environmental processes that have inhibited or interfered with the pursuit of that kind of life?' (Hayes et al., 2012, p. 106). The timeline of the problem should be established by considering its trajectory, antecedents and consequences (Hayes et al., 2012). The Flexibility Rating Sheet proposed by Hayes et al. (2012) can be used to help therapists structure their thoughts around a case formulation within the hexaflex framework of ACT.

ACT 3 (Values clarification): Inquiring about the extent to which employees are living according to their major life goals could enhance insight into the discrepancy between current behaviour and major life goals, and if facilitated correctly, can be used as a positive strength-based approach (Hayes et al., 2012). There is considerable overlap between the ACT definition of values and how Roberts and Robins (2000) typify major life goals. Given the brevity of the process, clarifying the employee's major life goals (broad agendas for major life domains) (Roberts \& Robins, 2000) can serve as a compass to establish more effective life patterns. Major life goals consist of economic goals, aesthetic goals, social goals, relationship goals, political goals, hedonistic goals, religious goals, personal growth goals, physical wellbeing goals and theoretical goals (Roberts \& Robins, 2000). Utilising major life goals is a pragmatic method of linking broad values to specific goals that can be advanced through the counselling process. Major life goals come with the added benefit of existing literature, situated in a nomological net that is associated with interest and personality research (Stoll, Einarsdóttir, Song, Ondish, Sun, \& Rounds, 2020).

A scene from ACT 3: A powerful ACT strategy to elicit major life goals is the eulogy exercise, which requires of clients to think about what they would like others to say about them at their funeral (Strosahl et al., 2004). Clients could also rank their major life goals to determine their most valued direction for the future.

Intermission: Homework is assigned after Session 1, to ensure further reflection and refinement of major life goal descriptions, in preparation for the subsequent session. Clients need to reflect on what would happen if they continue to struggle with the concerns that prevent the pursuit of 
TABLE 3: Brief acceptance and commitment therapy interventions.

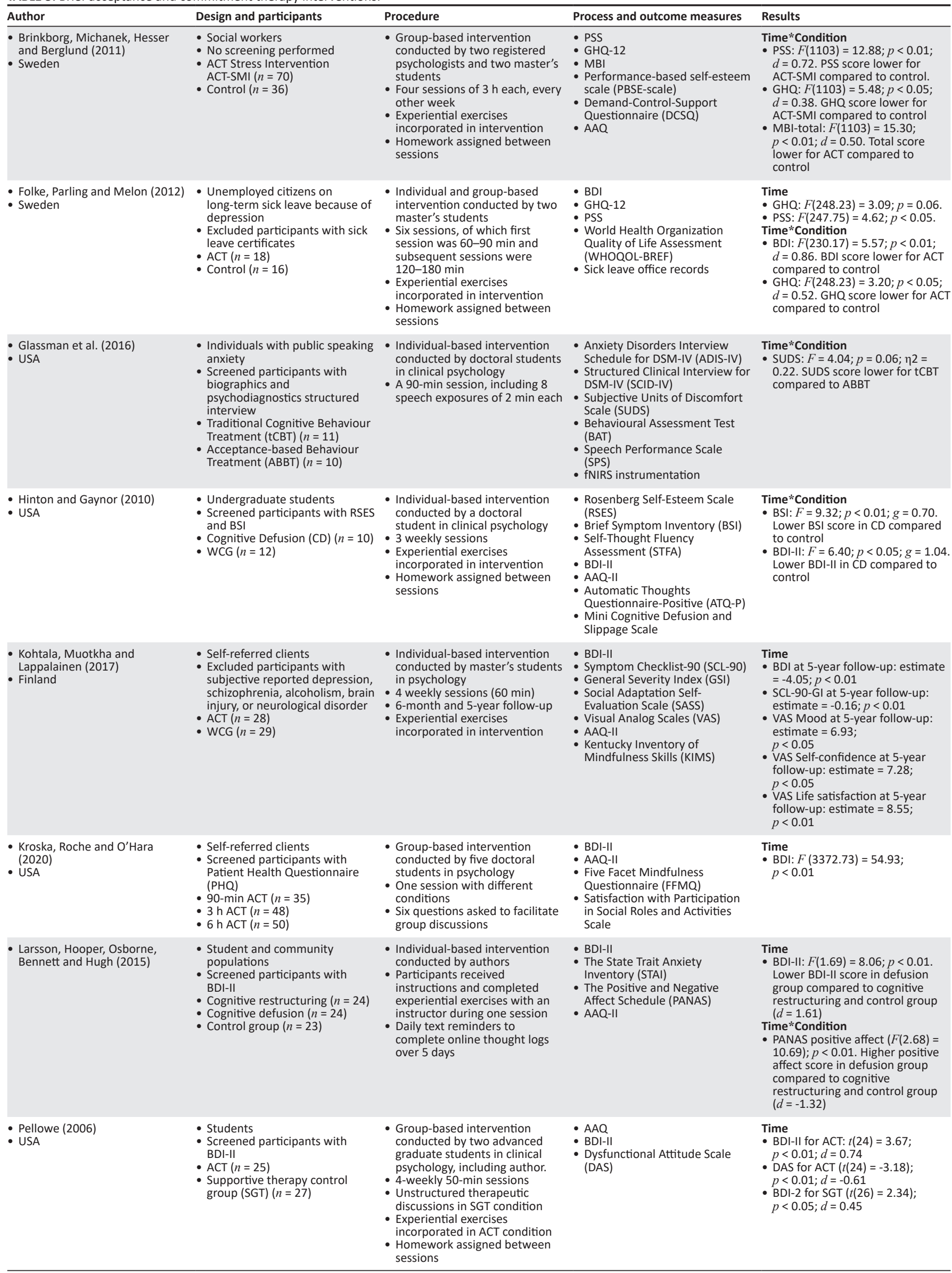


TABLE 3 (Continues...): Brief acceptance and commitment therapy interventions.

\begin{tabular}{|c|c|c|c|c|}
\hline Author & Design and participants & Procedure & Process and outcome measures & Results \\
\hline $\begin{array}{l}\text { - Ruiz et al. (2020) } \\
\text { - Spain }\end{array}$ & $\begin{array}{l}\text { - Self-identified clients } \\
\text { - Screened participants with Mini } \\
\text { International Neuropsychiatric } \\
\text { Interview } \\
\text { - Repetitive Negative } \\
\text { Thinking-Focussed (RNT) - ACT } \\
(n=23) \\
\text { - WCG }(n=25)\end{array}$ & $\begin{array}{l}\text { - Individual-based intervention } \\
\text { conducted by master's and } \\
\text { doctoral students in clinical } \\
\text { psychology } \\
\text { - Two weekly individual 60-min } \\
\text { sessions } \\
\text { - Experiential exercises } \\
\text { incorporated in intervention } \\
\text { - Homework included listening to } \\
\text { audio files } \\
\text { - Post measurement was a } \\
\text { 1-month follow-up }\end{array}$ & $\begin{array}{l}\text { - Depression, Anxiety, and Stress } \\
\text { Scales-21 (DASS-21) } \\
\text { - Perseverative Thinking } \\
\text { Questionnaire (PTQ) } \\
\text { - AAQ-II } \\
\text { - Cognitive Fusion Questionnaire } \\
\text { (CFQ) } \\
\text { - Valuing Questionnaire (VQ) } \\
\text { - Generalised Pliance } \\
\text { Questionnaire-9 (GPQ-9) }\end{array}$ & $\begin{array}{l}\text { Time*Condition } \\
\text { - DASS-21: } t(40.40)=6.11 ; \\
p<0.01 ; B=4.13,95 \% \mathrm{CI}[2.76, \\
5.49] \text {. Lower DAS-21 score for } \\
\text { RNT-ACT compared to control } \\
\text { ( } d=2.42) \\
\text { DASS-21 Depression: } t(40.05)= \\
\text { 3.30; } p<0.01 ; B=1.10 ; 95 \% \mathrm{Cl} \\
\text { [0.43, } 1.77] \text {. Lower depression } \\
\text { score for RNT-ACT compared to } \\
\text { control }(d=1.48) \\
\text { - DASS-21 Anxiety: } t(40.80)=5.62 ; \\
p<0.01 ; B=1.46 ; 95 \% \mathrm{Cl}[0.94 \text {; } \\
\text { 1.98]. Lower anxiety score for } \\
\text { RNT-ACT compared to control } \\
\text { ( } d=1.81) \\
\text { DASS-21 Stress: } t(130.89)=7.24 ; \\
p<0.01 ; B=1.64 ; 95 \% \mathrm{Cl}[1.19 \text {; } \\
\text { 2.08]. Lower stress score for } \\
\text { RNT-ACT compared to control } \\
(d=2.96)\end{array}$ \\
\hline
\end{tabular}

Note: Only significant effects or effects trending towards significance are reported for mood in Results column.

major life goals in comparison to what is possible when they can take steps in order to live closer to their values.

\section{Behavioural activation via specific goal-setting}

BOX 2: Behavioural activation via specific goal-setting.

- Supplement the value clarification process with setting specific goals, which serve as attainable targets to live values (Barrett \& Stewart, 2020; Brinkborg et al., 2011; Flaxman \& Bond, 2010; Kohtala et al., 2017; Kroska et al., 2020; Pellowe, 2006)

- Include strategies focussed on identifying actions plans to achieve therapeutic goals (Barrett \& Stewart, 2020; Brinkborg et al., 2011; Flaxman \& Bond, 2010; Kohtala et al., 2017; Pellowe, 2006).

ACT 4 (Setting specific goals): The identification of more specific therapeutic goals will assist employees to put major life goals into action (Kohtala et al., 2017). Counsellors are tasked with facilitating a process in which the client identifies specific goals that relate to their most valued major life goals. When setting specific goals, the employee must be guided to set self-directed, challenging, sufficiently complex, emotionally pleasing, meaningful and practically feasible goals to ensure the required self-efficacy and commitment to achieve such goals (Locke \& Latham, 2013; Van Lill, Roodt, \& De Bruin, 2020). If the therapeutic goals appear impractical or the client's expressed intention to pursue the therapeutic goals seem unconvincing, the counsellor should encourage further calibrations to the goals to enhance commitment. Visualising how life might be different when the therapeutic goals are achieved could also increase the client's motivation.

ACT 5 (Identifying and choosing actions): A clear comprehension of the outcomes to achieve should assist the employee to identify and commit to action strategies that can lead to change. The counsellor should start by considering the client's previous actions that were unsuccessful in achieving major life goals. Then the counsellor can discuss actions that will expand the client's behaviour repertoire, also referred to as target behaviours or goal-related behaviours (Scobbie, Dixon, \& Wyke, 2011) and guide the client to choose actions they can start implementing over the next week.
If and then statements might be a meaningful behavioural script that clients can adopt, instead of consciously thinking about every next action required to achieve therapeutic goals. An if statement could reflect a situation, to which a then statement would reflect an appropriate behavioural response that will lead to the achievement of a specific and distal major goal. These statements can assist in formulating the when, where and how of implementation intentions to concretise the achievement of goals (Gollwitcher \& Sheeran, 2006). For example, if I have the option of an elevator or stairs in a building (when and where related to a situation), then I will walk up the stairs (how). This will enable me to get more exercise at work (specific therapeutic goal) to live a healthy lifestyle (major life goal).

A scene from ACT 5: Generating creative hopelessness is a strategy to help clients to recognise their unsuccessful efforts to control problems in their lives (Hayes et al., 2012). The intention is for the client to realise that letting go of the struggle with the problem is the best way to pursue their values. 'The person in the hole exercise' could be a valuable intervention to illustrate how digging further will not get the client out of the hole (Strosahl et al., 2004). Instead, to live a life of value, the client needs to invest energy in pursuing major life goals.

Intermission: A homework assignment could include further reflection on the actions discussed during the session and as per Bond's (2004) recommendation, the client can draft a list of specific actions that will enhance committed action to achieve therapeutic goals.

\section{Developing psychological flexibility to address barriers}

BOX 3: Developing psychological flexibility to address barriers.

- Identification of barriers that prevent committed action (Brinkborg et al., 2011 Finnes et al., 2019; Flaxman \& Bond, 2010; Folke et al., 2012; Kohtala et al. 2017; Kroska et al., 2020)

- Enhance psychological flexibility by implementing the six processes of the hexaflex model (Barret \& Stewart, 2020; Bond \& Bunce, 2000; Finnes et al., 2019; Flaxman \& Bond, 2010; Folke et al., 2012; Glassman et al., 2016; Hinton \& Gaynor, 2010; Kroska et al., 2020; Larsson et al., 2015; Macías et al., 2019; Ruiz et al., 2020). 
ACT 6 (Identify barriers to goal pursuit): Barriers could include internal events (e.g. thoughts, feelings, memories and physical sensations) or external events (e.g. feedback from other people, contextual limitations and unexpected events) that undermine goal pursuits. Oettingen, Wittchen and Gollwitzer (2013) recommend a proactive approach to identifying possible challenges to goal pursuit to bolster the employee's implementation intentions and, consequently, goal achievement. The list of actions, compiled as homework for Session 2, can be extended to include a column of possible barriers that might undermine the achievement of valuedirected goals.

ACT 7 (Creating psychological flexibility): The six processes of the hexaflex model should be applied to assist clients in managing their identified barriers. Interventions aimed at facilitating acceptance can create a willingness to make room for barriers whilst continuing with committed action in a value-driven manner. Untangling cognitive fusion, being in contact with the present moment, and developing alternative perspectives on the self (Ruiz et al., 2020; Strosahl et al., 2004) can be utilised to address challenges that prevent intentions from becoming actions. If and then statements (discussed in ACT 5) might also be meaningful way to build contingencies around barriers to goal-directed behaviour.

A scene from ACT 7: The flip card exercise is a defusion strategy that involves the counsellor writing down troubling thoughts on cards and tossing them back to the client (Strosahl et al., 2004). Viewing thoughts that limit value-driven life on cards can create distance and help the client not to buy into the thoughts. Clients can first be asked to fight off the cards tossed by the counsellor and then allow them to fall in their laps to notice the difference between fighting cognitions and creating room for them.

Intermission: The homework assignment for Session 3 focuses on the implementation of the identified behavioural strategies. Counsellors can instruct clients to make specific notes about the effectiveness of the strategies and the barriers that came up and how they attempted to overcome them. This can serve as a feedback loop to revise goals or related action plans.

\section{Review of treatment and future directions}

BOX 4: Review of treatment and future directions.

- Reflect on highlights from intervention by inquiring about lessons that the clients learned and changes they were able to implement (Barrett \& Stewart, 2020; Folke et al., 2012)

- Encourage clients to continue with and expand on the committed actions that they have implemented through the counselling process (Barrett \& Stewart, 2020; Brinkborg et al., 2011; Finnes et al., 2019; Folke et al., 2012; Macías et al., 2019; Pellowe, 2006)

ACT 8 (Reviewing intervention): The first part of the final session is aimed at reviewing the identified goals and consequent behavioural intervention. There should be an evaluation of the employees' satisfaction with the progress they made in achieving their goals and the success of their behavioural strategies. The counsellor can inquire about any successes (even small ones) in goal achievement and the consequent impact on the client. Preparing the client for termination will be a segue into the final ACT, which concerns continuation of the gains obtained from counselling.

ACT 9 (Continuing committed action): Depending on the success of the committed action strategies, the counselling process will focus on adapting or expanding on the strategies. Successful implementation of committed action should be celebrated and reinforced, whilst future goals are discussed to extend the gains from counselling and prevent regression to an emphasis on the symptoms of anxiety and depression. Sustained implementable actions are required to continue goal achievement and maintain commitment to value-driven living. If employees have to actively choose a course of action in line with goals every time an alternative presents itself, it might deplete their self-regulatory resources (Oettingen et al., 2013). Work-based counsellors should help their clients to create habits (implementation intentions) that will automate goal-related actions and continue after the counselling process.

A scene from ACT 9: During the session, the counsellor can introduce a combination of breathing and visualisation exercises to encourage awareness, acceptance and nonjudgement towards inner experiences (Strosahl et al., 2004). The counsellor can encourage the client to incorporate these exercises as part of their daily routines to maintain a focus on their values and make room for challenging inner experiences.

\section{Limitations and recommendations}

This study concentrated on symptoms related to depression and anxiety but it could also be helpful to establish models to address other presentations of mental ill-being in the workplace. To focus the research, the literature review only considered ACT interventions. Investigating other available experimental designs could yield valuable information to inform work-based counselling processes. In addition, the non-significant differences between ACT and other forms of therapy found in literature Streams 2 and 3 might be explained by meta-therapeutic aspects at play in the social context of therapy that contribute to interventions' effectiveness (Wampold \& Imel, 2015). Future research endeavours could investigate the role and application of meta-therapeutic aspects as a contributing factor in the efficacy of work-based counselling.

The present study proposes broad theoretical parameters according to which an ACT protocol can be structured for industrial psychologists. Future studies could run randomised control trails to determine the effectiveness with which industrial psychologists can apply the protocol in 
order to assist clients with anxiety and depression, which will require pre- and post-assessments. Although all the studies incorporated in literature Streams 2 and 3 included pre- and post-counselling measurement of symptoms, ACT aims to improve psychological flexibility and symptom reduction is often a consequence of this primary aim (Gloster et al., 2020). For the purposes of further experimental research, it might be beneficial to validate and include a process measure, such as the WAAQ, as a measure of psychological flexibility.

\section{Conclusion}

With the global rise in mental health distress, industrial psychologists are bound to come across situations in the workplace where counselling is required. When considering the potential costs of mental health concerns for organisations, industrial psychologists have an obligation to their organisations, as well as an ethical duty as psychologists, to intervene when employees present with mental health challenges. Unfortunately, counselling has been a neglected area in the industrial psychology body of literature. The systematic literature review yielded multiple control trial studies that validated the benefits of ACT interventions in addressing anxiety and depressive symptoms in both clinical and work contexts. Based on available guidelines, the ACT for Work Well-being Model is proposed for use by industrial psychologists to offer a brief ACT intervention. The model is designed for further empirical testing, and the suggested guidelines should direct further investigations.

\section{Acknowledgements Competing interests}

The authors declare that they have no financial or personal relationships that may have inappropriately influenced them in writing this article.

\section{Authors' contributions}

X.v.L. and R.v.L conducted the literature review, analysed the data and developed the brief therapeutic model.

\section{Ethical considerations}

This article followed all ethical standards for research without direct contact with human or animal subjects.

\section{Funding information}

This research received no specific grant from any funding agency in the public, commercial, or not-for-profit sectors.

\section{Data availability}

The titles of the publications considered in the systematic literature review can be made available on request to the corresponding author, X.v.L.

\section{Disclaimer}

The views and opinions expressed in this article are those of the authors and do not necessarily reflect the official policy or position of any affiliated agency of the authors.

\section{References}

Barkhuizen, H., Jorgensen, L.I., \& Brink, L. (2014). Exploring the role of the industrialorganisational psychologist as counsellor. SA Journal of Industrial Psychology, 40(1), 1-11. https://doi.org/10.4102/sajip.v40i1.1193

Barkhuizen, H., Jorgensen, L.I., \& Brink, L. (2015). Training the industrial and organisational psychologist as counsellor: Are we doing enough? Acta Commercii, 15(1), 1-12. https://doi.org/10.4102/ac.v15i1.253

Barnard, G., \& Fourie, L. (2007). Exploring the roles and contributions of industrial psychologists in South Africa against a multi-dimensional conceptual framework (Part 2). SA Journal of Industrial Psychology, 33(2), 45-53. https://doi.org/10.4102/ sajip.v33i2.376

Barrett, K., \& Stewart, I. (2020). A preliminary comparison of the efficacy of online acceptance and commitment therapy (ACT) and cognitive behavioural therapy (CBT) stress management interventions for social and healthcare workers. Health and Social Care in the Community, 29(1), 1-14. https://doi.org/10.1111/ hsc. 13074

Bond, F.W. (2004). ACT for stress. In S.C. Hayes \& K. D. Strosahl (Eds.), A practical guide to acceptance and commitment therapy (pp. 275-293). New York, NY: Springer.

Bond, F.W., \& Bunce, D. (2000). Mediators of change in emotion-focused and problemfocused worksite stress management interventions. Journal of Occupational Health Psychology, 5(1), 156-163. https://doi.org/10.1037/1076-8998.5.1.156

Brinkborg, H., Michanek, J., Hesser, H., \& Berglund, G. (2011). Acceptance and commitment therapy for the treatment of stress among social workers: A randomized controlled trial. Behaviour Research and Therapy, 49(6-7), 389-398. https://doi.org/10.1016/j.brat.2011.03.009

Cantor, N. (1945). Employee counseling: A new viewpoint in industrial psychology. New York, NY: McGraw-Hill.

Cénat, J.M., Blais-Rochette, C., Kokou-Kpolou, C.K., Noorishad, P., Mukunzi, J.N., McIntee, S., ... Labelle, P. (2021). Prevalence of symptoms of depression, anxiety, insomnia, posttraumatic stress disorder, and psychological distress among populations affected by the COVID-19 pandemic: A systematic review and metaanalysis. Psychiatry Research, 295, 1-16. https://doi.org/10.1016/j. psychres.2020.113599

Collins, J., Gibson, A., Parkin, S., Parkinson, R., Shave, D., \& Dyer, C. (2012). Counselling in the workplace: How time-limited counselling can effect change in well-being. Counselling and Psychotherapy Research, 12(2), 84-92. https://doi.org/10.1080/ 14733145.2011.638080

Critical Appraisal Skills Programme. (2020). CASP randomised controlled trials checklist. Retrieved from https://casp-uk.net/casp-tools-checklists/

Dickson, W.J. (1945). The Hawthorne plan of personnel counseling. American Journal of Orthopsychiatry, 15(2), 343-347. https://doi.org/10.1111/j.1939-0025.1945. tb04947.x

Docrat, S., Besada, D., Cleary, S., Daviaud, E., \& Lund, C. (2019). Mental health system costs, resources and constraints in South Africa: A national survey. Health Policy and Planning, 34(9), 706-719. https://doi.org/10.1093/heapol/czz085

Dreyer, Z., Henn, C., \& Hill, C. (2019). Validation of the Depression Anxiety Stress Scale-21 (DASS-21) in a non-clinical sample of South African working adults. Journal of Psychology in Africa, 29(4), 346-353. https://doi.org/10.1080/1433023 7.2019.1647499

Du Plessis, M., \& Thomas, E. C. (2021). Counselling preparedness and responsiveness of industrial psychologists in the face of COVID-19. SA Journal of Industrial Psychology, 47, 1-13. https://doi.org/10.4102/sajip.v47i0.1860

Finnes, A., Ghaderi, A., Dahl, J., Nager, A., \& Enebrink, P. (2019). Randomized controlled trial of acceptance and commitment therapy and a workplace intervention for sickness absence due to mental disorders. Journal of Occupational Health Psychology, 24(1), 198-212. https://doi.org/10.1037/ocp0000097

Flaxman, P.E., \& Bond, F.W. (2010). A randomised worksite comparison of acceptance and commitment therapy and stress inoculation training. Behaviour Research and Therapy, 48(8), 816-820. https://doi.org/10.1016/j.brat.2010.05.004

Folke, F., Parling, T., \& Melin, L. (2012). Acceptance and commitment therapy for depression: A preliminary randomized clinical trial for unemployed on long-term sick leave. Cognitive and Behavioral Practice, 19(4), 583-594. https://doi. org/10.1016/j.cbpra.2012.01.002

Glassman, L.H., Forman, E.M., Herbert, J.D., Bradley, L.E., Foster, E.E., Izzetoglu, M., \& Ruocco, A.C. (2016). The effects of a brief acceptance-based behavioral treatment versus traditional cognitive-behavioral treatment for public speaking anxiety: An exploratory trial examining differential effects on performance and neurophysiology. exploratory trial examining differential effects on performance and neurophysiology.
Behavior Modification, 4O(5), 748-776. https://doi.org/10.1177/0145445516629939

Gloster, A.T., Walder, N., Levin, M.E., Twohig, M.P., \& Karekla, M. (2020). The empirical status of acceptance and commitment therapy: A review of meta-analyses. Journal of Contextual Behavioral Science, 18, 181-192. https://doi.org/10.1016/j jcbs.2020.09.009

Gollwitcher, P.M., \& Sheeran, P. (2006). Implementation intentions and goal achievement: A meta-analysis of effects and processes. Advances in Experimental Social Psychology, 38, 69-119. https://doi.org/10.1016/S0065-2601(06)38002-1 
Harvey, S.B., Modini, M., Joyce, S., Milligan-Saville, J.S., Tan, L., Mykletun, A., ... Mitchell, P.B. (2017). Can work make you mentally ill? A systematic meta-review of work-related risk factors for common mental health problems. Occupational and environmental risk factors for common mental health problems. Occupational and en
medicine, 74(4), 301-310. https://doi.org/10.1136/oemed-2016-104015

Hassem, T., \& Laher, S. (2019). A systematic review of online depression screening tools for use in the South African context. South African Journal of Psychiatry, 25, 1-8. https://doi.org/10.4102/sajpsychiatry.v25i0.1373

Hayes, S.C., Strosahl, K.D., Luoma, J., Varra, A.A., \& Wilson, K.G. (2004). ACT case formulation. In S.C. Hayes \& K.D. Strosahl (Eds.), A practical guide to acceptance and commitment therapy (pp. 59-73). New York, NY: Springer.

Hayes, S.F., Strosahl, K.D., \& Wilson, K.G. (2012). Acceptance and commitment therapy: The processes and practice of midnful change. New York, NY: Guilford Press.

Henn, C., \& Morgan, B. (2019). Differential item functioning of the CESDR-R and GAD 7 in African and white working adults. SA Journal of Industrial Psychology, 45, 1-10. https://doi.org/10.4102/sajip.v45i0.1663

Highhouse, S. (1999). The brief history of personnel counseling in industrialorganizational psychology. Journal of Vocational Behavior, 55(3), 318-336. https://doi.org/10.1006/jvbe.1999.1685

Hinton, M.J., \& Gaynor, S.T. (2010). Cognitive defusion for psychological distress, dysphoria, and low self-esteem: A randomized technique evaluation trial of vocalizing strategies. International Journal of Behavioral Consultation and Therapy, 6(3), 164-185. https://doi.org/10.1037/h0100906

HPCSA. (2019a). Minimum standards for the training of industrial psychology Retrieved from https://www.hpcsa.co.za/Uploads/PSB_2019/Policy\%20and\%20 Guidelines/SGB\%2OINDS\%20-\%20Revised\%200ctober\%202019.pdf

HPCSA. (2019b). Requirements in respect of internship programmes in industria psychology: Guidelines for universities, internship training institutions, and intern industrial psychologists. Retrieved from https://www.hpcsa.co.za/Uploads/ PSB_2019/Form $\% 20218 \% 20$ INDS $\% 20$ - $\% 2$ Requirements $\% 20$ in $\% 20$ Respect $\% 2$ of $\% 2$ Internship $\% 20$ Programmes $\% 20$ in $\% 2$ Industrial $\% 20$ sychology $\% 20 \% 20$.pdf

Jorgensen, L.I. (2016). Encounter group counsellor training with pre-service industrial psychologists: A pilot study. Journal of Psychology in Africa, 26(3), 300-303. https://doi.org/10.1080/14330237.2016.1185920

Jorgensen-Graupner, L.I., \& Van Zyl, L.E. (2019). Inspiring growth: A counselling framework for industrial psychology practitioners. In L.E. Van Zyl \& S. Rothmann ramework for industrial psychology practitioners. In L.E. Van Zyl \& S. Rothmann
(Eds.), Positive psychological intervention design and protocols for multi-cultural (Eds.), Positive psychological intervention design and protocols for multi-cultural
contexts (pp. 361-379). Heidelberg: Springer. https://doi.org/10.1007/978-3-030contexts

Kohtala, A., Muotka, J., \& Lappalainen, R. (2017). What happens after five years?: The long-term effects of a four-session acceptance and commitment therapy delivered by student therapists for depressive symptoms. Journal of Contextual Behavioral Science, 6(2), 230-238. https://doi.org/10.1016/j.jcbs.2017.03.003

Kroska, E.B., Roche, A.I., \& O'Hara, M.W. (2020). How much is enough in brief acceptance and commitment therapy? A randomized trial. Journal of Contextual Behavioral Science, 15, 235-244. https://doi.org/10.1016/j.jcbs.2020.01.009

Laher, S., \& Hassem, T. (2020). Doing systematic reviews in psychology. South African Journal of Psychology, 50(4), 450-468. https://doi.org/10.1177/0081246320956417

Larsson, A., Hooper, N., Osborne, L.A., Bennett, P., \& McHugh, L. (2015). Using brief cognitive restructuring and cognitive defusion techniques to cope with negative thoughts. Behavior Modification, 40(3), 452-482. https://doi. org/10.1177/0145445515621488

Lilienfeld, S.O., McKay, D., \& Hollon, S.D. (2018). Why randomised controlled trials of psychological treatments are still essential. The Lancet Psychiatry, 5(7), 536-538. https://doi.org/10.1016/S2215-0366(18)30045-2

Locke, E.A., \& Latham, G.P. (2013). Goal setting theory, 1990. In E.A. Locke \& G.P. Latham (Eds.), New developments in goal setting and task performance (pp. 3-15). New York, NY: Routledge.

Lundgren, T., Dahl, J., Melin, L., \& Kies, B. (2006). Evaluation of acceptance and commitment therapy for drug refractory epilepsy: A randomized controlled trial in
South Africa-A pilot study. Epilepsia, 47(12), 2173-2179. https://doi. South Africa-A pilot study. Epilepsid
org/10.1111/j.1528-1167.2006.00892.x

Macías, J., Valero-Aguayo, L., Bond, F.W., \& Blanca, M.J. (2019). The efficacy of functional-analytic psychotherapy and acceptance and commitment therapy (FACT) for public employees. Psicothema, 31(1), 24-29. https://doi.org/10.7334/ psicothema2018.202

Mall, S., Lund, C., Vilagut, G., Alonso, J., Williams, D.R., \& Stein, D.J. (2015). Days out of role due to mental and physical illness in the South African stress and health study. Social psychiatry and psychiatric epidemiology, 50(3), 461-468. https://doi. org/10.1007/s00127-014-0941-x

McLeod, J. (2010). The effectiveness of workplace counselling: A systematic review. Counselling and Psychotherapy Research, 10(4), 238-248. https://doi.org/10.108 0/14733145.2010.485688
Minjoo, K., Mpofu, E., Brock, K., Millington, M., \& Athanasou, J. (2014). Cognitivebehavioural therapy effects on employment-related outcomes for individuals with mental illness: A systematic review. SA Journal of Industrial Psychology, 40(2), 1-6. https://doi.org/10.4102/sajip.v40i2.1188

Nightingale, A. (2009). A guide to systematic literature reviews. Surgery, 27(9), 381-384. https://doi.org/10.1016/j.mpsur.2009.07.005

Oettingen, G., Wittchen, M., \& Gollwitzer, P.M. (2013). Regulating goal pursuit through mental contrasting with implementation intentions. In E.A. Locke \& G.P. Latham (Eds.), New developments in goal setting and task performance (pp. 523-548). New York, NY: Routledge.

Pellowe, M.E. (2006). Acceptance and commitment therapy as a treatment for dysphoria. Unpublished Doctoral Thesis, University of Wyoming, Laramie, WY.

Pomaki, G., Franche, R.L., Murray, E., Khushrushahi, N., \& Lampinen, T.M. (2012). Workplace-based work disability prevention interventions for workers with common mental health conditions: A review of the literature. Journal of Occupational Rehabilitation, 22(2), 182-195. https://doi.org/10.1007/s10926Occupation

Roberts, B.W., \& Robins, R.W. (2000). Broad dispositions, broad aspirations: The intersection of personality traits and major life goals. Personality and Social Psychology Bulletin, 26(10), 1284-1296. https://doi.org/10.1177/0146167200262009

Ruiz, F.J., Peña-Vargas, A., Ramírez, E. S., Suárez-Falcón, J. C., García-Martín, M. B. García-Beltrán, D.M., ... Sánchez, P.D. (2020). Efficacy of a two-session repetitive negative thinking-focused acceptance and commitment therapy (ACT) protocol for depression and generalized anxiety disorder: A randomized waitlist contro trial. Psychotherapy, 57(3), 444-456. https://doi.org/10.1037/pst0000273

Scobbie, L., Dixon, D., \& Wyke, S. (2011). Goal setting and action planning in the rehabilitation setting: Development of a theoretically informed practice framework. Clinical Rehabilitation, 25(5), 468-482. https://doi.org/10.1177/ 0269215510389198

Siddaway, A.P., Wood, A.M., \& Hedges, L.V. (2018). How to do a systematic review: A best practice guide for conducting and reporting narrative reviews, meta-analyses, and meta-syntheses. Annual Review of Psychology, 70(1), 747-770. https://doi. org/10.1146/annurev-psych-010418-102803

Stepanek, M., Jahanshahi, K., \& Millard, F. (2019). Individual, workplace, and combined effects modeling of employee productivity loss. Journal of Occupationa and Environmental Medicine, 61(6), 469-478. https://doi.org/10.1097/ JOM.0000000000001573

Stoll, G., Einarsdóttir, S., Song, Q.C., Ondish, P., Sun, J.J., \& Rounds, J. (2020). The roles of personality traits and vocational interests in explaining what people want out of life. Journal of Research in Personality, 86, 103939. https://doi.org/10.1016/j. jrp.2020.103939

Strosahl, K.D., Hayes, S.C., Wilson, K.G., \& Grifford, E.V. (2004). An ACT primer: Core therapy processes, intervention, and therapist competencies. In S.C. Hayes \& K.D. Strosahl (Eds.), A practical guide to acceptance and commitment therapy (pp. 31-58). New York, NY: Springer.

Strosahl, K.D., Robinson, P.J., \& Gustavsson, T. (2012). Brief interventions for radical change: Principles and practice of focused acceptance and commitment therapy. Oakland, CA: New Harbinger Publications.

Strümpfer, D. (2007). Lest we forget that industrial and organisational psychology is psychology. SA Journal of Industrial Psychology, 33(1), 1-7. https://doi. org/10.4102/sajip.v33i1.257

Van Lill, X., Roodt, G., \& de Bruin, G.P. (2020). Is there a general factor in goal commitment? SA Journal of Industrial Psychology, 46, 1-10. https://doi. org/10.4102/sajip.v46i0.1765

Van Vuuren, L.J. (2010). Industrial psychology: Goodness of fit? Fit for goodness?. SA Journal of Industrial Psychology, 36(2), 1-16. Retrieved from https://hdl.handle. net/10520/EJC89224

Van Zyl, L.E., Nel, E., Stander, M.W., \& Rothmann, S. (2016). Conceptualising the professional identity of industrial or organisational psychologists within the South African context. SA Journal of Industrial Psychology, 42(1), 1-13. https://doi. org/10.4102/sajip.v42i1.1379

Wampold, B.E., \& Imel, Z.E. (2015). The great psychotherapy debate: The evidence for what makes psychotherapy work. New York, NY: Routledge.

Wilensky, J.L., \& Wilensky, H.L. (1951). Personnel counseling: The Hawthorne case. American Journal of Sociology, 57(3), 265-280. https://doi.org/10.1086/220945

World Health Organization. (2017). Depression and other common mental disorders: Global health estimates. Retrieved from https://apps.who.int/iris/bitstream/ handle/10665/254610/WHO-MSD-MER-2017.2-eng.pdf

World Health Organization. (2020). Mental health: Burden. Retrieved from https:// www.who.int/health-topics/mental-health\#tab=tab_2 